ARTICLE

\title{
Organophotocatalytic selective deuterodehalogenation of aryl or alkyl chlorides
}

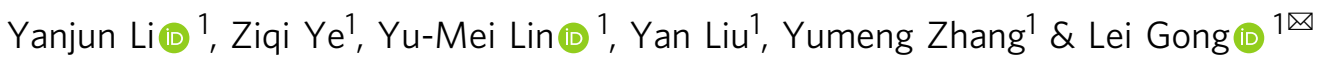

Development of practical deuteration reactions is highly valuable for organic synthesis, analytic chemistry and pharmaceutic chemistry. Deuterodehalogenation of organic chlorides tends to be an attractive strategy but remains a challenging task. We here develop a photocatalytic system consisting of an aryl-amine photocatalyst and a disulfide co-catalyst in the presence of sodium formate as an electron and hydrogen donor. Accordingly, many aryl chlorides, alkyl chlorides, and other halides are converted to deuterated products at room temperature in air (>90 examples, up to $99 \%$ D-incorporation). The mechanistic studies reveal that the aryl amine serves as reducing photoredox catalyst to initiate cleavage of the $\mathrm{C}-\mathrm{Cl}$ bond, at the same time as energy transfer catalyst to induce homolysis of the disulfide for consequent deuterium transfer process. This economic and environmentally-friendly method can be used for site-selective D-labeling of a number of bioactive molecules and direct $H / D$ exchange of some drug molecules.

\footnotetext{
${ }^{1}$ Key Laboratory of Chemical Biology of Fujian Province, iChEM, College of Chemistry and Chemical Engineering, Xiamen University, Xiamen 361005 Fujian, China. ${ }^{凶}$ email: gongl@xmu.edu.cn
} 
D euterium-containing molecules are widely used in investigation of reaction mechanisms ${ }^{1-7}$, organic synthesis $^{8-12}$, analytic chemistry ${ }^{13-15}$, and pharmaceutic chemistry $^{16-19}$. In particular, D-labeling techniques have been established as an important tool in drug development because incorporation of deuterium atoms into bioactive compounds can dramatically affect their metabolic and pharmacokinetic properties $^{20,21}$. In 2017, Austedo (deutetrabenazine) was approved by FDA as the first deuterated drug used for the treatment of chorea, a dyskinesia associated with Huntington's disease $^{22}$. Our knowledge of the distribution, metabolism and excretion properties of a number of drugs such as Tolperisone, Rofecoxib and Dasatinib has been remarkably enhanced by deuteration (Fig. 1a) 23,24. Development of practical and biofriendly deuteration protocols, in particular those being applicable to structurally complex pharmaceutical compounds, is of great interests and in high demand ${ }^{25-37}$.

Deuterodehalogenation of organohalides is a straightforward strategy with which to incorporate deuterium atoms at specific positions. However, the available methods often rely on transition-metal catalysis and suffer from harsh reaction conditions, narrow substrate scope, and the use of toxic and expensive deuterium sources ${ }^{38}$. Achieving a high level of deuterium incorporation is also a challenging task ${ }^{39}$. These factors apparently limit their application in pharmaceutic and life science. Recently, several subtle strategies have been developed to avoid use of transition metal catalysts $40-44$. For example, Renaud et al. reported thiol-catalyzed deuterative deiodination of alkyl iodides with $\mathrm{D}_{2} \mathrm{O}$ as a source of deuterium atoms with a stoichiometric amount of $\mathrm{Et}_{3} \mathrm{~B}$ as the reductant ${ }^{40}$. Liu et al. developed potassium methoxide/disilane-mediated deuterodehalogenation of (hetero) aryl bromides or iodides in $\mathrm{CD}_{3} \mathrm{CN}^{41}$. Loh et al. developed the photocatalytic deuterodehalogenation of aryl halides using porous $\mathrm{CdSe}$ nanosheets as the catalyst and $\mathrm{D}_{2} \mathrm{O}$ as the deuteration reagent ${ }^{42}$. Organic chlorides tend to be less expensive, more abundant and readily available than other halides. There are however very limited methods for deuterodehalogenation of aryl chlorides $^{45,46}$, and to date, deuterodehalogenation of unactivated alkyl chlorides has not been reported. Several significant challenges are associated with the strategy, including (i) the highly negative reduction potentials of unactivated $\mathrm{C}-\mathrm{Cl}$ bonds (for example, $E_{\text {red }}\left[\left(\mathrm{CH}_{3} \mathrm{CH}_{2} \mathrm{CH}_{2} \mathrm{Cl}\right) /\left(\mathrm{CH}_{3} \mathrm{CH}_{2} \mathrm{CH}_{2} \mathrm{Cl}\right)^{--}\right]=-2.8 \mathrm{~V}$ vs $\mathrm{SCE})^{47-52}$, (ii) the strong possibility of side reactions such as elimination in transition metal catalysis ${ }^{53}$, (iii) the lack of an effective approach to deuterium transfer which can ensure a high incorporation of deuterium ${ }^{29}$. Moreover, precise differentiation of $\mathrm{C}-\mathrm{Cl}$ bonds in polychlorinated compounds that have little or no difference in polarity or other features is highly useful in multistep organic syntheses of deuterated biomolecules, but remains an unsolved problem (Fig. 1b).

Our group has long had an interest in the design of economic and environmentally-friendly photochemical synthesis ${ }^{54-58}$. We questioned whether implementing reducing organophotoredox catalysis could initiate the cleavage of unactivated aryl/alkyl $\mathrm{C}-\mathrm{Cl}$ bonds, and well-matched organocatalysis could bridge the energy gap between the $\mathrm{O}-\mathrm{D}$ bonds in $\mathrm{D}_{2} \mathrm{O}\left(\mathrm{BDE}=118 \mathrm{kcal} \mathrm{mol}^{-1}\right)$ and $\mathrm{C}-\mathrm{D}$ bonds in deuterated hydrocarbons $\left(\mathrm{BDE}=88-110 \mathrm{kcal} \mathrm{mol}^{-1}\right)^{29}$. This would allow us establish an effective channel for deuterium transfer, suppressing side reactions, and developing a general and convenient D-labeling method.

Herein, we report photocatalytic deuterodehalogenation for both aryl and alkyl chlorides by synergistic aryl-amine-based organophotoredox and disulfide organocatalysis in the presence of sodium formate as a mild electron and hydrogen sacrificial agent. This reaction provides a practical access to structurally diverse deuterated products including many bioactive molecules and drugs, and exhibits excellent siteselectivity in deuterodehalogenation of polychlorinated compounds which would be beneficial for the assembly of libraries of deuterated compounds (Fig. 1c).

\section{Results}

Reaction development. Aryl amines have been established as useful photoredox catalysts in some light-induced reactions ${ }^{59,60}$. We questioned whether adjusting structures of conjugated aryl amines would enable us find effective visible-light photocatalysts for deuterodehalogenation of organic chlorides. For example, 1,3,5-tris ( $4^{\prime}$-( $N, N$-dimethylamino)phenyl)benzene (PC1, Fig. 2) has been intensively used as chemo-sensors ${ }^{61}$. To investigate their applications in synthetic chemistry, photophysical and electrochemical properties of PC1 and PC2-PC4 were measured and summarized in Fig. 2, including the maximum absorption, excitation, the energies of the first singlet excited state $\left(E_{0,0}\right)$, and the oxidation potentials at excited state $\left(E_{\text {ox }}^{*}\right)$. These compounds exhibited obvious visible-light absorption (see more details in Supplementary Fig. 15), long excited-state lifetimes (2-24 ns), and strongly reducing ability ( $E_{\text {ox }}^{*}=-1.61$ to $-2.71 \mathrm{~V}$ vs $\mathrm{SCE}$ ), which allowed them serve as catalyst candidates being capable of cleaving unactivated $\mathrm{C}\left(\mathrm{sp}^{2}\right)-\mathrm{Cl}$ and $\mathrm{C}\left(\mathrm{sp}^{3}\right)-\mathrm{Cl}$ bonds $\left(E_{\text {red }}=-1.8\right.$ to $-3.0 \mathrm{~V})$, and initiating radical process under visible light conditions.

We embarked on an examination of photocatalytic deuterodehalogenation reactions by using PC1 ( $5 \mathrm{~mol} \%$ ) as a photocatalyst, propane-1-thiol $(30 \mathrm{~mol} \%)$ as the co-catalyst for deuterium atom transfer $25,62,4$-chloro-1,1'-biphenyl (1a, $E_{\text {red }}=$ $-2.30 \mathrm{~V}$ vs SCE in DMSO) as the model substrate, and $\mathrm{D}_{2} \mathrm{O}$ as the deuterium source. Upon irradiation with a $50 \mathrm{~W}$ blue LEDs lamp $\left(\lambda_{\max }=400 \mathrm{~nm}\right)$ at room temperature, the reaction of 1a with excess $\mathrm{D}_{2} \mathrm{O}$ in DMSO produced only a trace amount of $\mathbf{2 a}$ (Fig. 3, entry 1). The reaction could be improved to some extent by the addition of inorganic bases, which provided low to moderate conversion and deuterium incorporation (entries 2-4). It was thought that introduction of certain reductive hydrogen donor could tune the reactivity of the catalytic cycles and improve the efficiency of the reaction. The Hantzsch ester was found to be inappropriate for this transformation (entry 5), but formate salts accelerated the reaction significantly and led to an obvious increase in the deuterium incorporation (entries 6-8). Sodium formate was identified as the best additive, delivering in $15 \mathrm{~h}$ the product (2a) in quantitative yield and with $85 \%$ deuterium incorporation (D-inc.) (entry 6). The result of using sodium formate to promote the transfer of electrons and hydrogen atoms is fully consistent with the observation in the intermolecular addition of aryl and heteroaryl radicals to enecarbamate substrates reported recently by Jui et al. ${ }^{63}$. Other sulfurcontaining cocatalysts such as ethyl 2-mercaptoacetate (entry 9), 4-methoxybenzenethiol (entry 10), dicyclohexyl disulfide (entry 11), dipropyl disulfide (entry 12), dimethyl disulfide (entry 13), and diethyl disulfide were examined. The D-incorporation was significantly improved $(92 \% \mathrm{D}$-inc.) by replacing the thiol with dimethyl disulfide (entry 13). The higher reaction efficiency might be attributed to the fact that in contrast to the thiols, organic disulfides can be easily cleaved into free thiyl radicals useful in the deuterium transfer without introduction of additional protons ${ }^{64}$. Photocatalysts PC2-PC4 could be used in the reaction, while gave reduced yields or/and deuterium incorporation (entries 16-18). Control experiments revealed that the photocatalyst and the light irradiation were essential for the reaction to proceed (entries 19, 20), and the sulfur-based cocatalyst was critical for achieving a high level of deuterium incorporation (entry 21). 
a<smiles>CCCCC1CN2CCc3cc(OC(=O)OCc4ccccc4)c(OC(=O)[O-])cc3CC2C1=O</smiles>

deutetrabenazine

(Austedo)<smiles>[2H]c1nc(Nc2nc(C(=O)Nc3c(C)cccc3Cl)cc(N3CCN(CCO)CC3)n2)sc1C</smiles>

deuterated Dasatinib<smiles>[2H]c1nc([2H])c([2H])c(-c2cc(NC[C@H](C)c3ccc4c(C(=O)N[O+])ccnc4c3)ncn2)n1</smiles>

VX-984

b

- highly negative $E_{\text {red }}(-1.8--3.0 \mathrm{~V})$ of C-Cl bonds - strong tendency to side reactions
- functionality compatibility

- site-selectivity

C

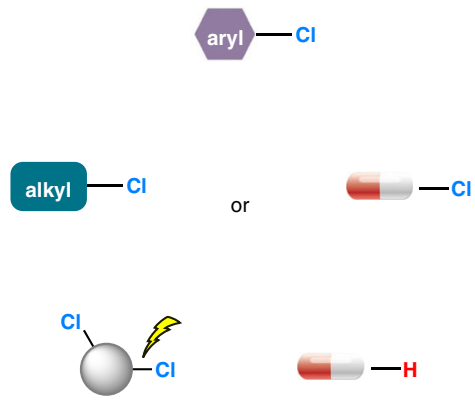

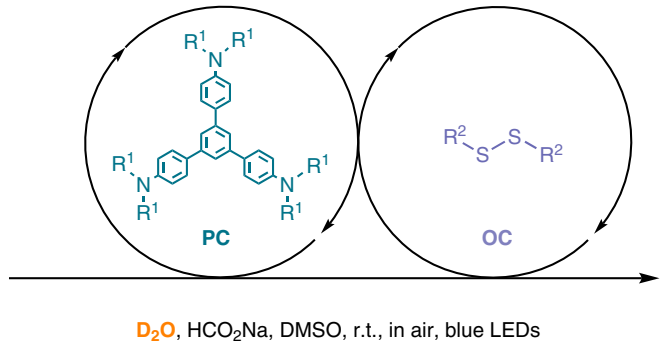

PC: $E_{\text {ox }}^{*}=-1.6--2.7 \mathrm{~V}, \tau=2-24 \mathrm{~ns}$, photoredox \& energy transfer
$\mathbf{R}-\mathrm{D}$

$>90$ examples

high D-inc. \& site-selectivity D-labeling of biomolecules<smiles>CC(C)(Oc1ccc(Cl)cc1)C(=O)OCC[18OH]</smiles><smiles>[2H]c1ncccc1C(=O)OCCOC(=O)C(C)(C)Oc1ccc(Cl)cc1</smiles><smiles>[2H]Cc1ccc(C(=O)OC2C3OC(C)(C)OC3O[C@H]2[C@H]2COC(C)(C)O2)cc1</smiles><smiles>O=C(Nc1ccccc1-c1ccc(Cl)cc1)c1cccnc1</smiles><smiles>[2H]c1ccc(C2=CC[C@@H]3[C@H]4CC=C5C[C@@H](OC(C)=O)CC[C@]5(C)[C@@H]4CC[C@]23C)cn1</smiles>

Fig. 1 Overview of this work. a Deuterated drug molecules. b Challenges in deuterodehalogenation of organic chlorides and its application to drug labeling. c This work: organophotocatalytic selective deuterodehalogenation of aryl or alkyl chlorides. LG, leaving group; PC, photocatalyst; OC, organocatalyst; r.t., room temperature; D-inc., deuterium incorporation; DMSO, dimethyl sulfoxide.

Reaction scope of aryl chlorides and other halides. With the optimal conditions in hand, the substrate scope of the photocatalytic deuterodehalogenation of aryl chlorides was investigated (Fig. 4). Products bearing a phenyl substituent (2a), a fused ring $(\mathbf{2 b}, \mathbf{2 c})$ or an electron-withdrawing group (2d-2f) were formed within $10-12 \mathrm{~h}$ from the chlorobenzene derivatives $(67-86 \%$ yield, $83-97 \%$ D-inc.). 1-Chloro-4-methoxybenzene failed to provide the desired product $(\mathbf{2 g})$ when using $\mathbf{P C} \mathbf{1}$ as the 


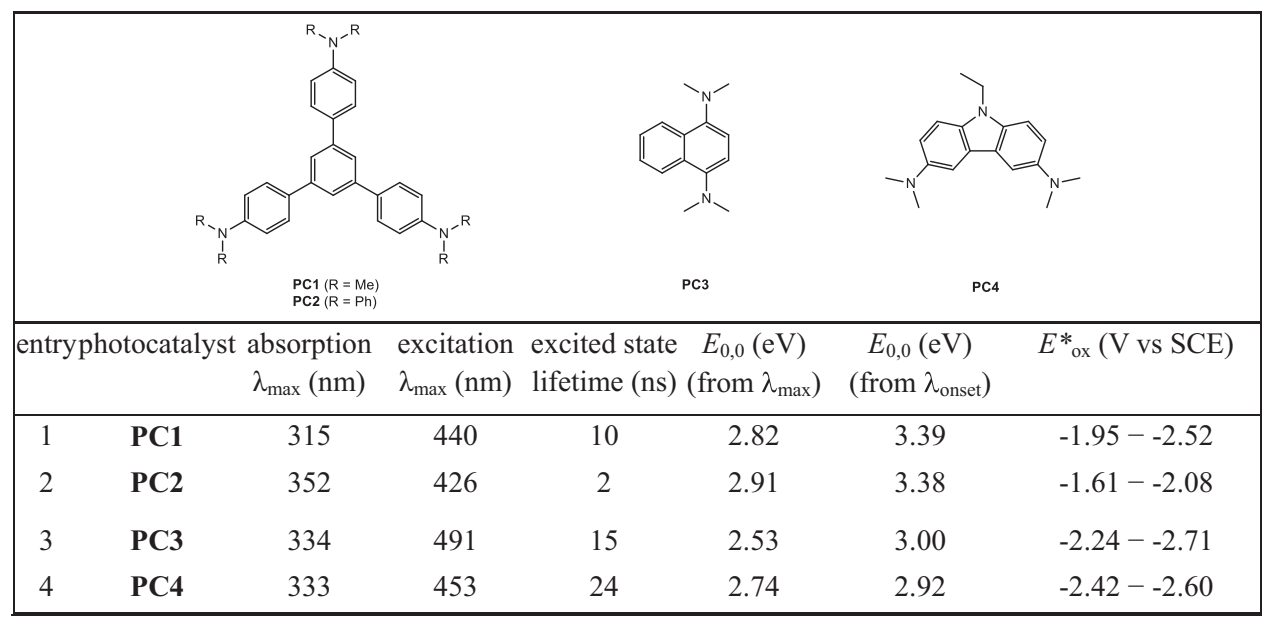

Fig. 2 Photophysical and electrochemical properties of arylamine-based photocatalysts PC1 - PC4. All the data are measured in DMSO (0.10 or $1.0 \mathrm{mM}$ ) solution at room temperature. PC, photocatalyst; DMSO, dimethyl sulfoxide.

\begin{tabular}{|c|c|c|c|c|c|c|}
\hline \multirow[b]{2}{*}{ entry } & \multicolumn{3}{|c|}{ 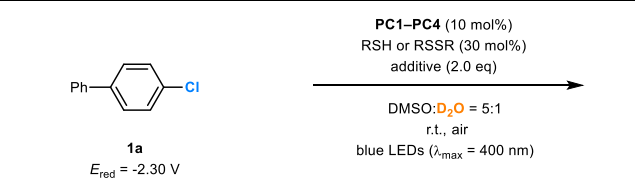 } & \multicolumn{2}{|c|}{ 2a } & \multirow[b]{2}{*}{ D-inc. $(\%)^{b}$} \\
\hline & PC & RSH or RSSR & additive & $\mathrm{t}(\mathrm{h})$ & conv. $(\%)^{\mathrm{a}}$ & \\
\hline 1 & PC1 & $n \mathrm{PrSH}$ & none & 15 & $<5$ & n.d. \\
\hline 2 & PC1 & $n \mathrm{PrSH}$ & $\mathrm{Na}_{2} \mathrm{CO}_{3}$ & 15 & 77 & 20 \\
\hline 3 & PC1 & $n \mathrm{PrSH}$ & $\mathrm{NaOAc}$ & 15 & 60 & 10 \\
\hline 4 & PC1 & $n \mathrm{PrSH}$ & $\mathrm{Na}_{3} \mathrm{PO}_{4}$ & 15 & 57 & 16 \\
\hline 5 & PC1 & $n \mathrm{PrSH}$ & Hantzsch ester & 15 & 0 & n.a. \\
\hline 6 & PC1 & $n \mathrm{PrSH}$ & $\mathrm{HCO}_{2} \mathrm{Na}$ & 15 & quant. & 85 \\
\hline 7 & PC1 & $n \mathrm{PrSH}$ & $\mathrm{HCO}_{2} \mathrm{~K}$ & 15 & quant. & 84 \\
\hline 8 & PC1 & $n \mathrm{PrSH}$ & $\mathrm{HCO}_{2} \mathrm{NH}_{4}$ & 15 & quant. & 73 \\
\hline 9 & PC1 & ethyl 2-mercaptoacetate & $\mathrm{HCO}_{2} \mathrm{Na}$ & 9 & quant. & 53 \\
\hline 10 & PC1 & 4-MeOPhSH & $\mathrm{HCO}_{2} \mathrm{Na}$ & 9 & 90 & 24 \\
\hline 11 & PC1 & $(\mathrm{CyS})_{2}$ & $\mathrm{HCO}_{2} \mathrm{Na}$ & 9 & 69 & 6 \\
\hline 12 & PC1 & $(n \operatorname{PrS})_{2}$ & $\mathrm{HCO}_{2} \mathrm{Na}$ & 9 & quant. & 91 \\
\hline 13 & PC1 & $(\mathrm{MeS})_{2}$ & $\mathrm{HCO}_{2} \mathrm{Na}$ & 9 & quant. & 92 \\
\hline 14 & PC1 & $(\mathrm{EtS})_{2}$ & $\mathrm{HCO}_{2} \mathrm{Na}$ & 9 & 85 & 92 \\
\hline 15 & PC1 & $(n \mathrm{BuS})_{2}$ & $\mathrm{HCO}_{2} \mathrm{Na}$ & 9 & 66 & 9 \\
\hline 16 & PC2 & $(n \operatorname{PrS})_{2}$ & $\mathrm{HCO}_{2} \mathrm{Na}$ & 9 & 26 & 92 \\
\hline 17 & PC3 & $(n \mathrm{PrS})_{2}$ & $\mathrm{HCO}_{2} \mathrm{Na}$ & 9 & 36 & 84 \\
\hline 18 & PC4 & $(n \operatorname{PrS})_{2}$ & $\mathrm{HCO}_{2} \mathrm{Na}$ & 9 & 51 & 81 \\
\hline 19 & none & $(\mathrm{MeS})_{2}$ & $\mathrm{HCO}_{2} \mathrm{Na}$ & 25 & $<5$ & n.d. \\
\hline $20^{\mathrm{c}}$ & PC1 & $(\mathrm{MeS})_{2}$ & $\mathrm{HCO}_{2} \mathrm{Na}$ & 25 & 0 & n.d. \\
\hline 21 & PC1 & none & $\mathrm{HCO}_{2} \mathrm{Na}$ & 25 & 90 & 10 \\
\hline
\end{tabular}

Fig. 3 Initial experiments for photocatalytic deuterodehalogenation of aryl chlorides. Reaction conditions: 1 a $(0.10 \mathrm{mmol}), \mathrm{D}_{2} \mathrm{O}(0.10 \mathrm{~mL}), \mathbf{P C 1}-\mathbf{P C 4}$ $(0.0050 \mathrm{mmol})$, thiol or disulfide $(0.030 \mathrm{mmol})$, additive $(0.20 \mathrm{mmol})$, DMSO $(0.50 \mathrm{~mL})$, a $50 \mathrm{~W}$ blue LEDs lamp $\left(\lambda_{\max }=400 \mathrm{~nm}\right)$, room temperature $\left(\sim 30^{\circ} \mathrm{C}\right.$ under irradiation), in air. ${ }^{a}$ Degree of conversion determined by ${ }^{1} \mathrm{H}-\mathrm{NMR}$. b ${ }^{\mathrm{D}}$-inc. determined by ${ }^{1} \mathrm{H}-\mathrm{NMR}$. ${ }^{\mathrm{C}}$ In the dark. PC, photocatalyst; eq, equivalent; r.t., room temperature; conv., conversion; D-inc., deuterium incorporation; t, reaction time; quant., quantitative conversion; n.d., not determined; n.a., not applicable; DMSO, dimethyl sulfoxide.

photocatalyst, perhaps because the electron-rich chlorobenzene contains the $\mathrm{C}\left(\mathrm{sp}^{2}\right)-\mathrm{Cl}$ bond with higher reduction potential $\left(E_{\text {red }}=-2.90 \mathrm{~V}\right.$ vs SCE in DMSO). This transformation could be improved by replacing PC1 by PC4 of stronger reducing ability $\left(E^{*}{ }_{\text {ox }}=-2.42\right.$ to $\left.-2.60 \mathrm{~V}\right)$, delivering $2 \mathrm{~g}$ in $74 \%$ yield and with $63 \%$ D-inc. Aromatic heterocycles are common in organic compounds including natural products and bioactive molecules, and a number of pharmaceutically important heterocyclic chlorides were examined and found to be well tolerated under the standard conditions. For example, deuterated heterocycles including pyridines with an electron-donating substituent (product $\mathbf{2 i}$ ) or an electron-withdrawing substituent (products $\mathbf{2 j - 2 o}$ ), 


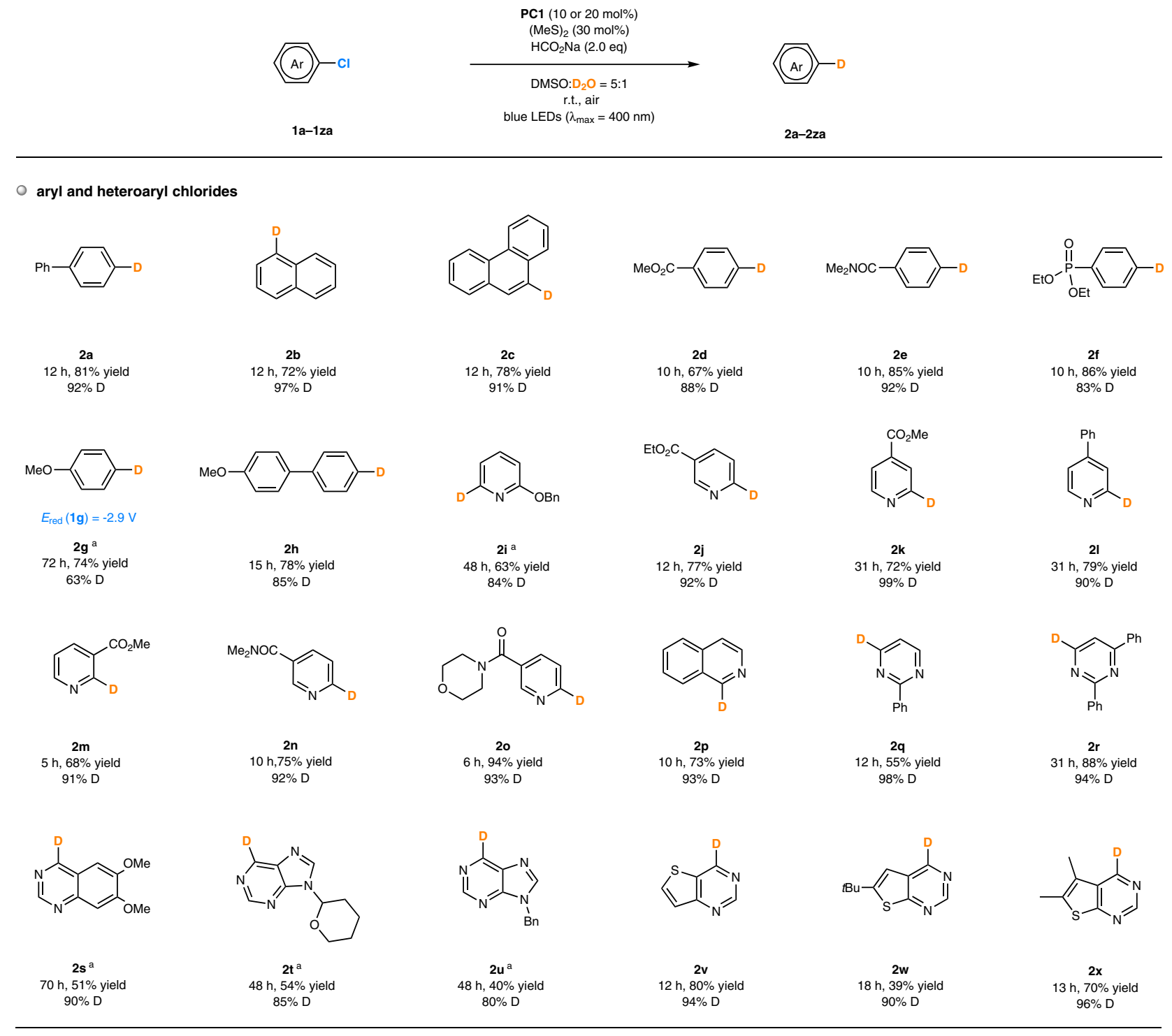

aryl bromides and iodides<smiles>[2H]c1cc2ccccc2c2ccccc12</smiles>

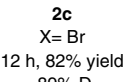

$89 \%$ yiel

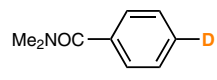

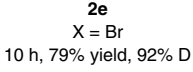<smiles>[2H]c1cccc(C2(C)OCCO2)n1</smiles>

$2 y$
$X=B r$

$72 \mathrm{~h}, 86 \%$ yield, $85 \%$ D

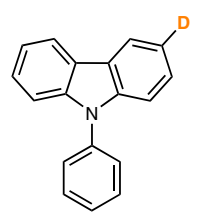

$\mathbf{2 z}$

$18 \mathrm{~h}, 90 \%$ yield, $87 \% \mathrm{D}$

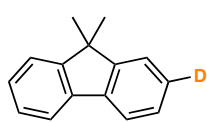

$2 z a$
$X=B r$

$15 \mathrm{~h}, 75 \%$ yield, $95 \% \mathrm{D}$

Fig. 4 Scope of photocatalytic deuterodehalogenation of aryl chlorides and other halides. aPC4 $(20 \mathrm{~mol} \%),(n P r S)_{2}(30 \mathrm{~mol} \%)$, in argon. $\mathrm{PC}$, photocatalyst; r.t., room temperature; eq, equivalent; DMSO, dimethyl sulfoxide.

isoquinoline (product $\mathbf{2 p}$ ), pyrimidines (products $2 \mathbf{q}, \mathbf{2 r}$ ), quinazoline (product 2s), purines (products $2 \mathbf{t}, 2 \mathbf{u}$ ), thieno[3,2-d] pyrimidine (product $\mathbf{2 v}$ ) and thieno[2,3- $d$ ]pyrimidines (products $2 \mathbf{w}, 2 \mathrm{x}$ ) were all obtained in reasonable yields (39-94\%) and with excellent deuterium incorporation (80-99\%). These results also revealed the excellent functionality compatibility of the reaction, which could be useful in its further application to structurally more complex pharmaceutical molecules and drugs ${ }^{35}$. Moreover, this method was applicable to other aryl halides. For example, the D-labeled products (2c, 2e, 2y-2za) could be obtained by the reaction of the corresponding aryl bromides or iodides under the standard conditions, providing similar deuterium incorporation while increasing the reaction rates.

Deuterodehalogenation of alkyl chlorides. Unactivated alkyl chlorides are particularly resistant to deuterodehalogenation. The traditional transition-metal catalytic approaches are not applicable due to the possibility of side reactions such as $\beta$ elimination. The highly negative reduction potentials of $\mathrm{C}\left(\mathrm{sp}^{3}\right)$ $\mathrm{Cl}$ bonds and the reactive intermediates eliminate them from the scope of radical-mediated methods ${ }^{65}$. For these reasons, 


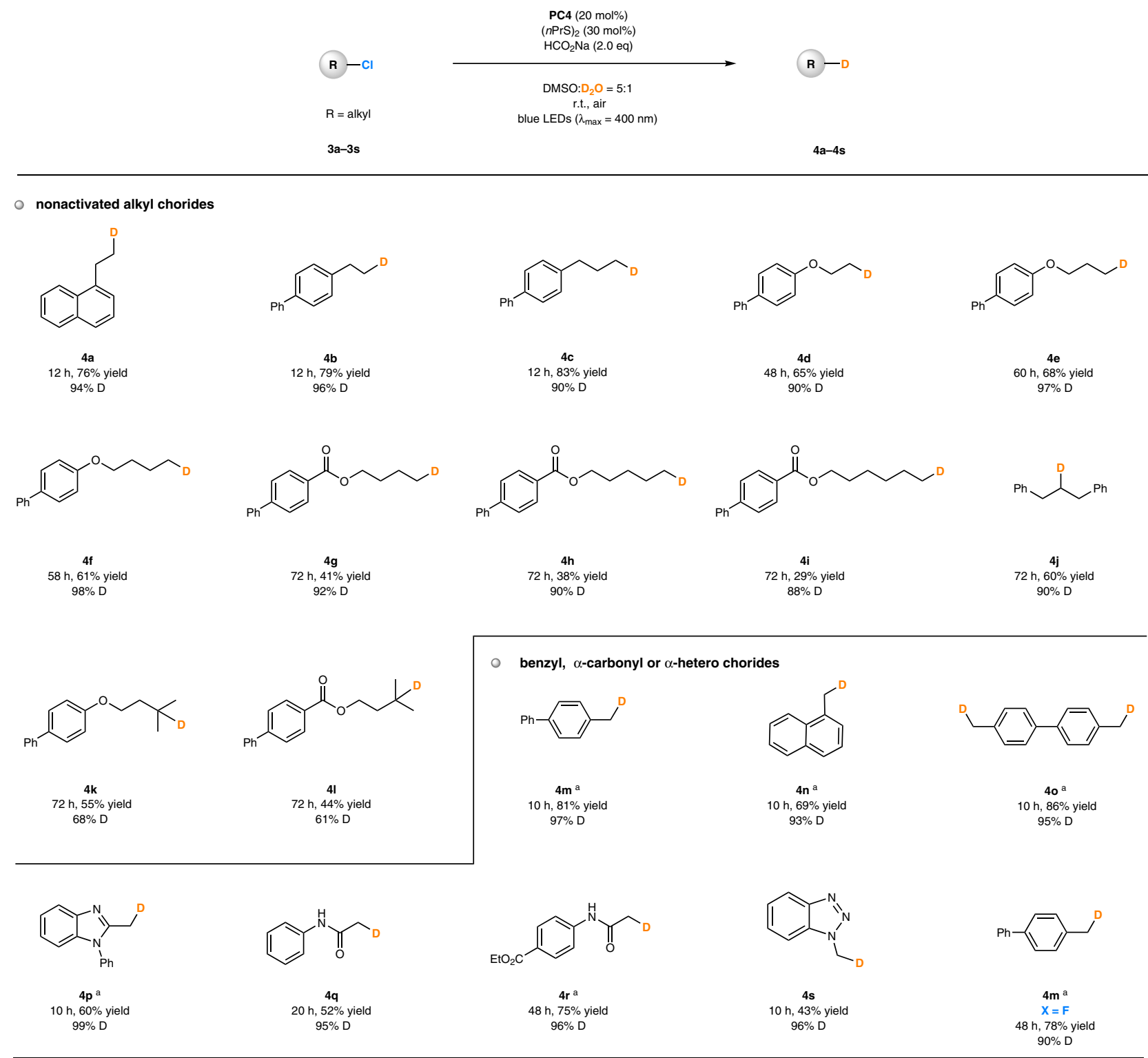

Fig. 5 Scope of photocatalytic deuterodehalogenation of alkyl chlorides. aPC4 (10 mol\%). PC, photocatalyst; r.t., room temperature; eq, equivalent; DMSO, dimethyl sulfoxide.

deuterodehalogenation of unactivated alkyl chlorides has not been reported to date.

To our delight, the photochemical deuterodehalogenation reaction of $3 \mathbf{a}$, a terminal alkyl chloride, gave the desired deuterated product (4a) in $76 \%$ yield and with $94 \%$ deuterium incorporation within $12 \mathrm{~h}$ in the presence of PC4 $\left(E^{*}{ }_{\text {ox }}=-2.42\right.$ to $-2.60 \mathrm{~V}$ vs SCE) as the photocatalyst (see more details for reinvestigation of reaction conditions in Supplementary Table 2). A number of unactivated alkyl chlorides were examined under the developed reaction conditions (Fig. 5). Primary alkyl chlorides bearing a remote aromatic ring (products $4 \mathbf{a}-\mathbf{4 c}$ ), an ether bond (products 4d-4f) or an ester linkage (products 4g-4i) all provided the deuterated products in reasonable yields (29-83\%) and with high deuterium incorporation (88-98\%). The secondary alkyl chloride also reacted, delivering product $4 \mathrm{j}$ in $60 \%$ yield and with $90 \% \mathrm{D}$-inc. In comparison, the tertiary alkyl chlorides were less effective substrates, whose reactions proceeded much more slowly and provided $\mathbf{4 k}, 4 \mathbf{1}$ with 68 and $61 \% \mathrm{D}$-inc., respectively. Relatively active $\mathrm{C}\left(\mathrm{sp}^{3}\right)-\mathrm{Cl}$ precursors containing a benzyl group

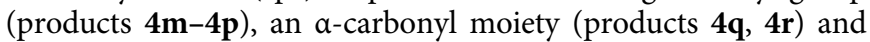

a-hetero substitutent (products $4 \mathbf{s}$ ) were found to be excellent substrates in photocatalytic deuterodehalogenation. These reactions proceeded more rapidly (typically at a lower catalyst loading) and resulted in higher deuterium incorporation (93-99\%). The neighboring effects even enabled the reductive cleavage of $\mathrm{C}-\mathrm{F}$ followed by deuteration, affording product $4 \mathrm{~m}$ from a fluorine-containing starting material.

Site-selective deuterodehalogenation of polychlorinated compounds. Selective funtionalization of carbon-halogen bonds with little or no difference in polarity and other features in polyhalogenated compounds is a highly desirable attribute in multistep organic synthesis but remains highly challenging ${ }^{66-69}$. It was found that this photocatalytic system could selectively install one deuterium atom in dichlorinated or polychlorinated compounds through choice of a photocatalyst with appropriate reducing ability, that is important for rapid construction of deuterated molecule arrays through diverse functionalization of the residual C-Cl bonds (Fig. 6). For example, under the standard conditions and in the presence of PC1 or PC2 as the photocatalyst, the 

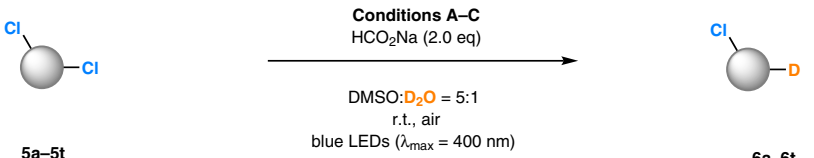

6a-6t

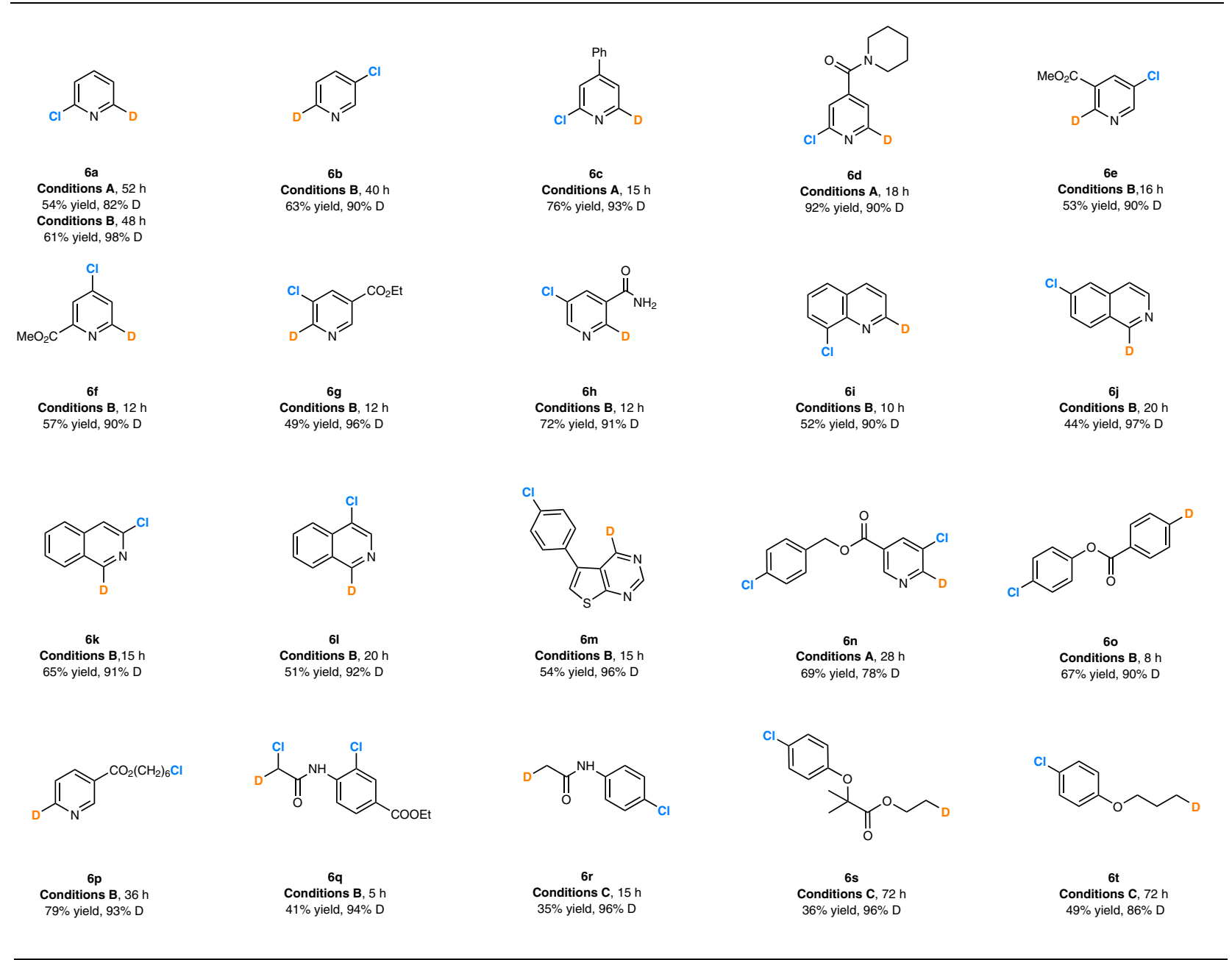

a gram-scale synthesis of deuterated Zytiga via selective deuterodechlorination
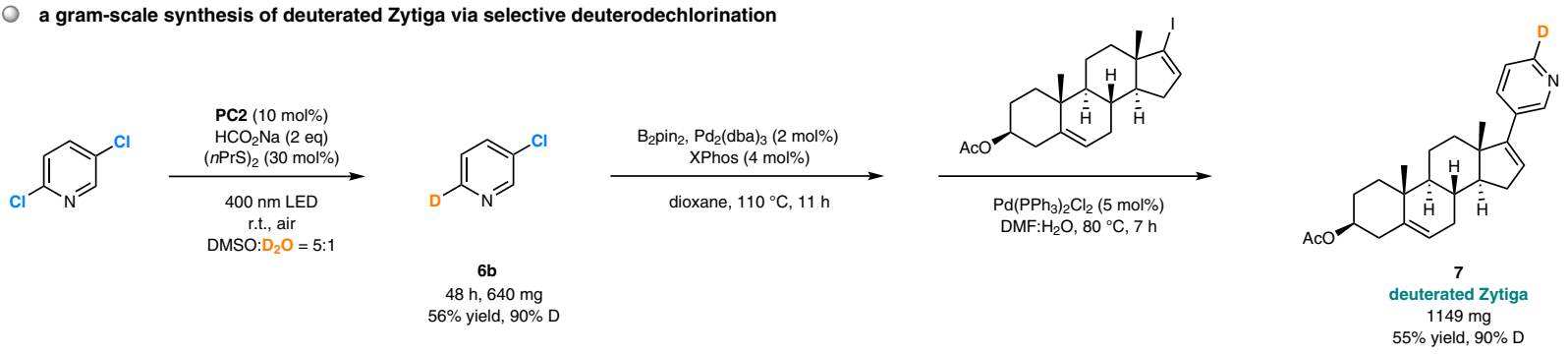

Fig. 6 Site-selective deuterodehalogenation of polychlorides. Conditions A: PC1 (10 mol\%), (MeS) 2 (30 mol\%). Conditions B: PC2 (10 mol\%), $(n P r S)_{2}$ (30 mol\%). Conditions C: PC4 (20 mol\%), (nPrS) 2 (30 mol\%). PC, photocatalyst; r.t., room temperature; eq, equivalent; DMSO, dimethyl sulfoxide; DMF, $\mathrm{N}, \mathrm{N}$-dimethylformamide; $\mathrm{B}_{2} \mathrm{pin}_{2}$, Bis(pinacolato)diboron.

reactions of symmetric dichlorinated pyridine derivatives (5a $\mathbf{- 5 d}$ ) only afforded monodeuterated compounds $(\mathbf{6 a - 6 d})$ in $61-$ $92 \%$ yield and with $90-98 \%$ D-inc. Prolonged reaction time did not lead to the formation of dideuterated products. Excellent siteselectivity could be observed for a number of unsymmetric (hetero)aryl chlorides, all of which provided monodeuterated products (6e-6o) with high deuterium incorporation (78-97\%). Typically, a C-Cl bond at $\alpha$-positions next to the nitrogen atom in pyridines, diazines or quinolines was more readily to be reacted, which is a hot spot for aldehyde oxidase (AOX) metabolism ${ }^{70}$. Assemble of deuterium atoms at these positions in drugs would be useful for pharmacokinetic investigations. Moreover, selective deuterodehalogenation of compounds bearing both $\mathrm{C}\left(\mathrm{sp}^{2}\right)-\mathrm{Cl}$ and $\mathrm{C}\left(\mathrm{sp}^{3}\right)-\mathrm{Cl}$ bonds could be accessed as well. For example, photocatalyst PC2 enabled attachment of one deuterium atom to the pyridyl moiety of $\mathbf{5 p}$ and delivered product $\mathbf{6 p}$ with $93 \%$ 
a
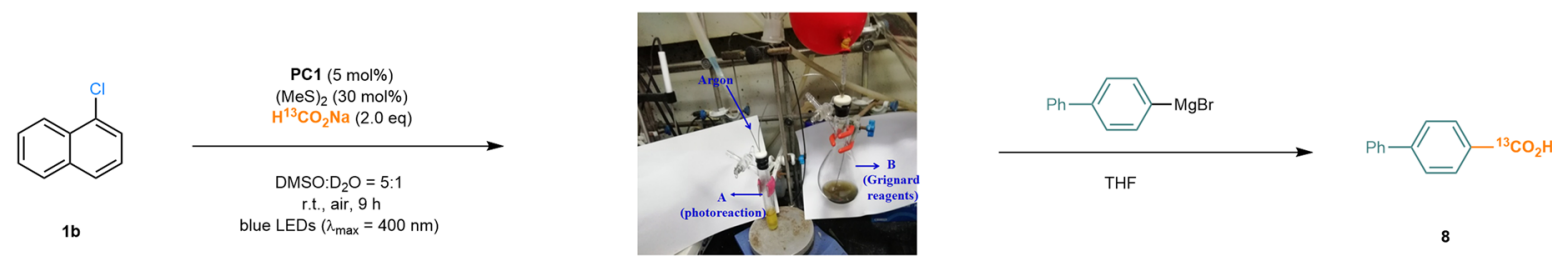

releasing gaseous byproduct

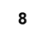

$33 \%$ yield

b

Quenching of PC1

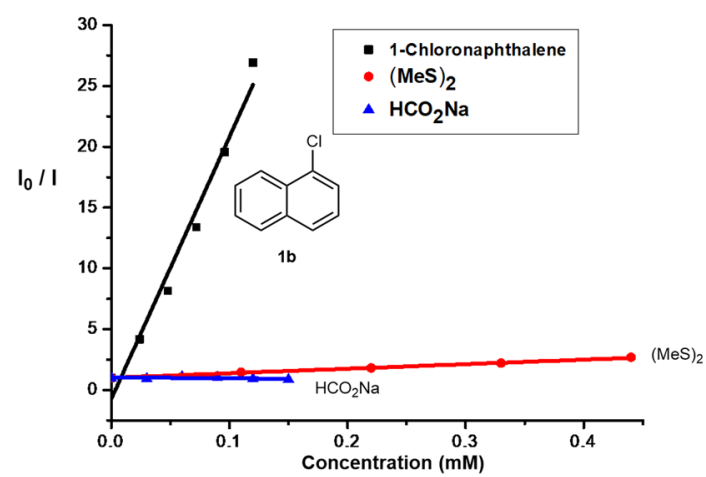

Quenching of PC4

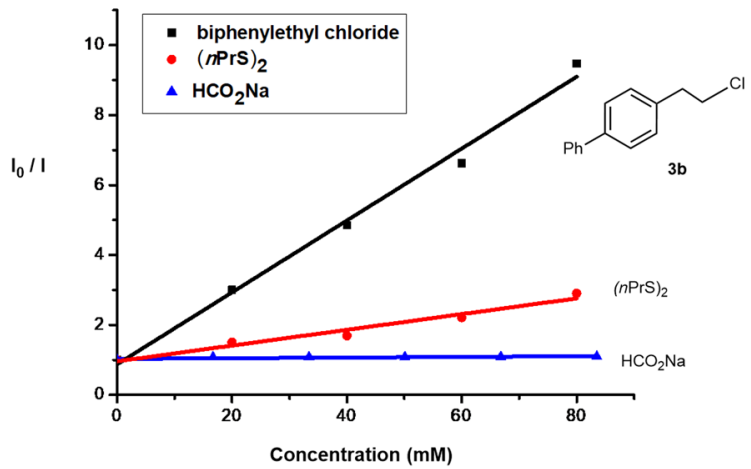

c

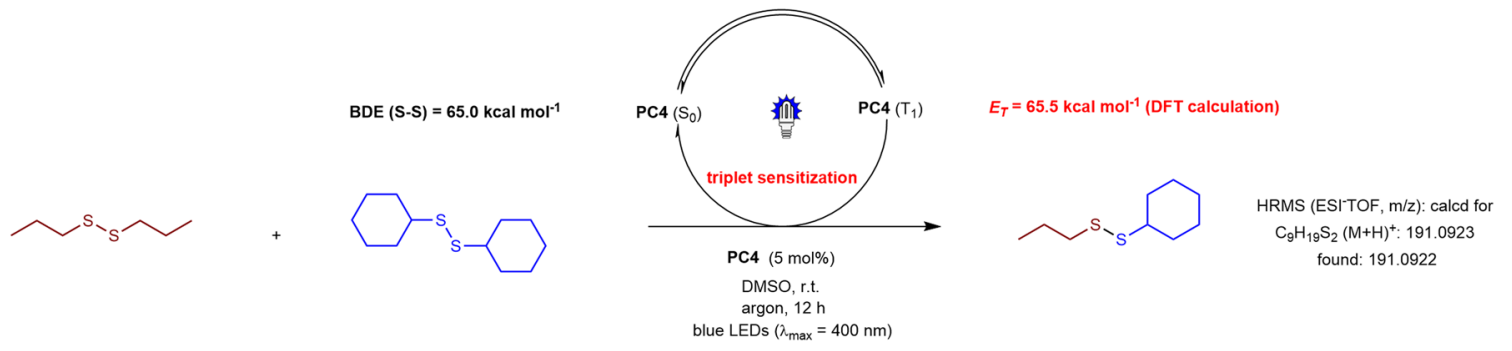

d
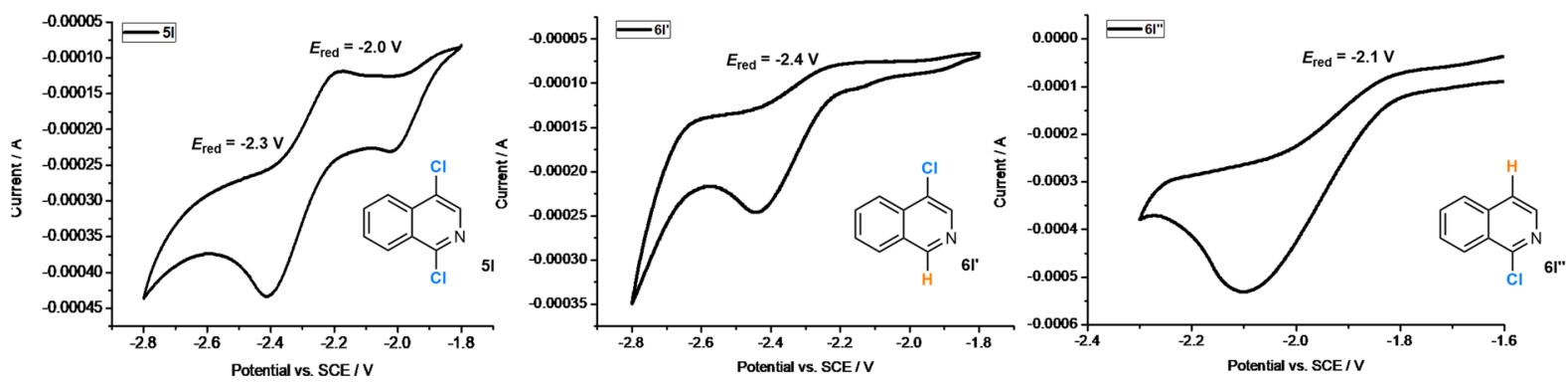

Fig. 7 Mechanistic studies. a $\mathrm{CO}_{2}$ trapping experiments. b Stern-Volmer quenching experiments. c Thiyl radical scrambling experiments. d Cyclic voltammetry of the dichloride and the possible mono reduction products. PC, photocatalyst; r.t., room temperature; eq, equivalent; THF, tetrahydrofuran; DMSO, dimethyl sulfoxide; DFT, density functional theory; BDE, bond dissociation energy; SCE, saturated calomel electrode.

D-inc., while photocatalyst PC4 offered an opportunity to introduce deuterium atoms on the alkyl chains instead of on the electron-rich phenyl rings in $\mathbf{5 r}-\mathbf{5 t}$ (86-96\% D-inc.). Such a transformation has not been realized by other reported methods, and will provide a useful access to selectively incorporate deuterium atoms in complex halogen-containing biomolecules as well as drugs. For example, Zytiga is a specific medicine for the treatment of patients with metastatic castration-resistant prostate cancer or high-risk castration-sensitive prostate cancer ${ }^{71}$, and was the 46th drug in retail sales in $2019^{72}$. A gram-scale synthesis of D-labeled Zytiga 7 (1149 mg, 90\% D-inc.) could be readily developed based on the selective deuterodehalogenation of 2,5-dichoropyridine (product 6b) followed by Pd-catalyzed coupling reactions.

Mechanistic studies. Several control experiments were conducted to gain some insight into the mechanism of this reaction (Fig. 7). 


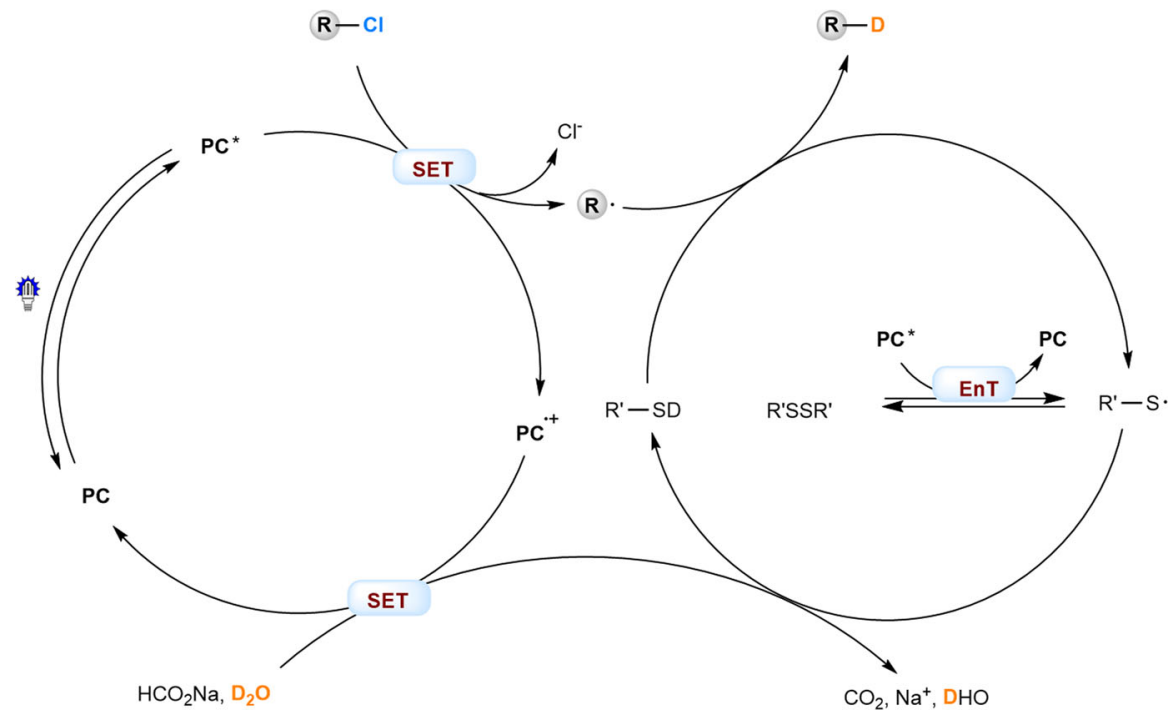

Fig. 8 Proposed reaction mechanism. The photocatalysts are introduced as strongly reducing photoredox catalysts to initiate cleavage of $\mathrm{C}-\mathrm{Cl}$ bonds, at the same time as energy transfer catalysts to induce homolysis of the disulfide cocatalysts. PC, photocatalyst; SET, single electron transfer; EnT, energy transfer.

The photochemical reaction $\mathbf{1} \mathbf{b} \rightarrow \mathbf{2 b}$ under the standard conditions with the ${ }^{13} \mathrm{C}$-labeled sodium formate $\left(\mathrm{H}^{13} \mathrm{CO}_{2} \mathrm{Na}\right)$ led to the formation of ${ }^{13} \mathrm{CO}_{2}$, which was trapped by a Grignard reagent to afford the ${ }^{13} \mathrm{C}$-containing $p$-phenylbenzoic acid (8) in $33 \%$ yield (Fig. 7a). This observation confirmed that sodium formate serves as an essential electron donor (a reductant) in the catalytic cycles with release of $\mathrm{CO}_{2}$ as a byproduct. Luminescence quenching experiments revealed that the aryl chloride (1b) was capable of obviously quenching the excited state of PC1 (Fig. 7b, left). The disulfide cocatalyst $(\mathrm{MeS})_{2}$ somewhat quenched its excited state as well while sodium formate failed to do so, revealing the possible interactions between the photocatalyst and other reaction components. The similar results were observed in a system of photocatalyst PC4, alkyl chloride 3b, 1,2-dipropyldisulfane and sodium formate (Fig. $7 \mathrm{~b}$, right).

A radical scrambling experiment was performed to probe the existence of thiyl radical intermediates in the photochemical reaction. Under the standard conditions and in the presence of the photocatalyst PC4, irradiation of dipropyl disulfide and dicyclohexyl disulfide with blue light led to the observation by HRMS of cyclohexyl propyl disulfane (Fig. 7c). The formation of cyclohexyl propyl disulfane probably involved thiyl radicals as intermediates and saw their radical recombination or radical addition into another disulfide molecule. Density functional theory calculations further established that an energy transfer between alkyl disulfides (BDE (S-S) $=65.0 \mathrm{kcal} \mathrm{mol}^{-1}$ ) and the photocatalyst $\left(E_{T}(\mathbf{P C} 4)=65.5 \mathrm{kcal} \mathrm{mol}^{-1}\right)$ was energetically favorable in the reaction (see more details in Supplementary Method 4.8 $)^{73}$.

Electrochemical analysis of one dichlorinated starting material (51), $\mathrm{H}$-analogs of the possible regioisomeric products $\left(\mathbf{6 l}^{\prime}, \mathbf{6 l}^{\prime \prime}\right)$ was performed (Fig. 7d). Two reversible reduction/oxidation signals were observed at $E_{\text {red }}=-2.3 \mathrm{~V}$ and $-2.0 \mathrm{~V}$ for 51 . The reversible reduction peaks of $\mathbf{6 l}^{\prime}$ and $\mathbf{6} \mathbf{l}^{\prime \prime}$ were found at $-2.4 \mathrm{~V}$ and $-2.1 \mathrm{~V}$, respectively. These outcomes suggested that $\mathrm{C}-\mathrm{Cl}$ bond at $\alpha$-position of the isoquinoline moiety was more active than that at the other position, and $\mathbf{6} \mathbf{l}^{\prime}$ was more resistant to further reductive deuterodehalogenation. However, the electronic properties and bond dissociation energies $(\mathrm{BDE}(\mathrm{C}-\mathrm{Cl})=88.7$ vs $84.3 \mathrm{kcal} \mathrm{mol}^{-1}$ ) are close to each other, demonstrating that this photocatalytic system has precise recognition ability toward these similar C-Cl bonds (see more details in Supplementary Method 4.9).

Mechanistic proposal. On basis of the initial experiments and these mechanistic studies, a plausible mechanism for the photocatalytic deuterodehalogenation of organochlorides is shown in Fig. 8. The photoexcited catalyst $\left(\mathbf{P C}^{*}, E^{*}{ }_{\text {ox }}=-1.61\right.$ to $-2.71 \mathrm{~V}$ vs SCE) undergoes single electron transfer with the organic chloride $\left(E_{\text {red }}=-1.8\right.$ to $\left.-3.0 \mathrm{~V}\right)$ to give rise to $\mathbf{P C}^{+}+$and a carbon radical $\left(\mathrm{R}_{\bullet}\right)$. Meanwhile, PC* $^{*}$ serve as an energy transfer catalyst $\left(E_{T}(\mathbf{P C 4})=65.5 \mathrm{kcal} \mathrm{mol}^{-1}\right)$ to induce homolysis of the disulfides (BDE $(\mathrm{S}-\mathrm{S})=65.0 \mathrm{kcal} \mathrm{mol}^{-1}$ ) affording a thiyl radical (R'S•). In combination with sodium formate as the electron donor and hydrogen donor, R'S• performs effective deuterium atom transfer, and close both the photocatalytic and organocatalytic cycles.

Synthetic application to D-labeled bioactive molecules and drugs. Since the developed photocatalytic system exhibits excellent functional group compatibility and broad substrate scope, we questioned whether it could be used for deuterium-labeling of more complex bioactive molecules and drug derivatives (Fig. 9). For example, Etofibrate is a compound produced by the combination of clofibrate ester linked to niacin, and is used to treat hyperlipemia $^{74}$. Photocatalytic deuterodehalogenation of its chlorinated derivatives with PC1 as the photocatalyst under the standard conditions led to selective incorporation of deuterium atoms into Etofibrate at specific positions of the pyridyl moiety without affecting the chlorine atoms on the electronically rich phenyl ring, and delivered deuterated products $(\mathbf{9}, \mathbf{1 0})$ with 91 and $90 \% \mathrm{D}$-inc., respectively. Using a similar strategy, deuterated Nikethamide (11), Pyriproxifen (12), and Nicoboxil (13) were obtained in good yields $(64-86 \%)$ and with high deuterium incorporation (86-99\%). Boscalid from BASF is a nicotinamide germicide, which has a broad spectrum of bactericidal activity and has a preventative effect, being active against many types of fungal diseases ${ }^{75}$. Under the standard conditions, the $\mathrm{C}\left(\mathrm{sp}^{2}\right)-\mathrm{Cl}$ bond located on the pyridyl moiety of Boscalid was selectively converted into a C-D bond, affording a product (14) in $89 \%$ yield and with $88 \%$ deuterium incorporation. Deuterodehalogenation 

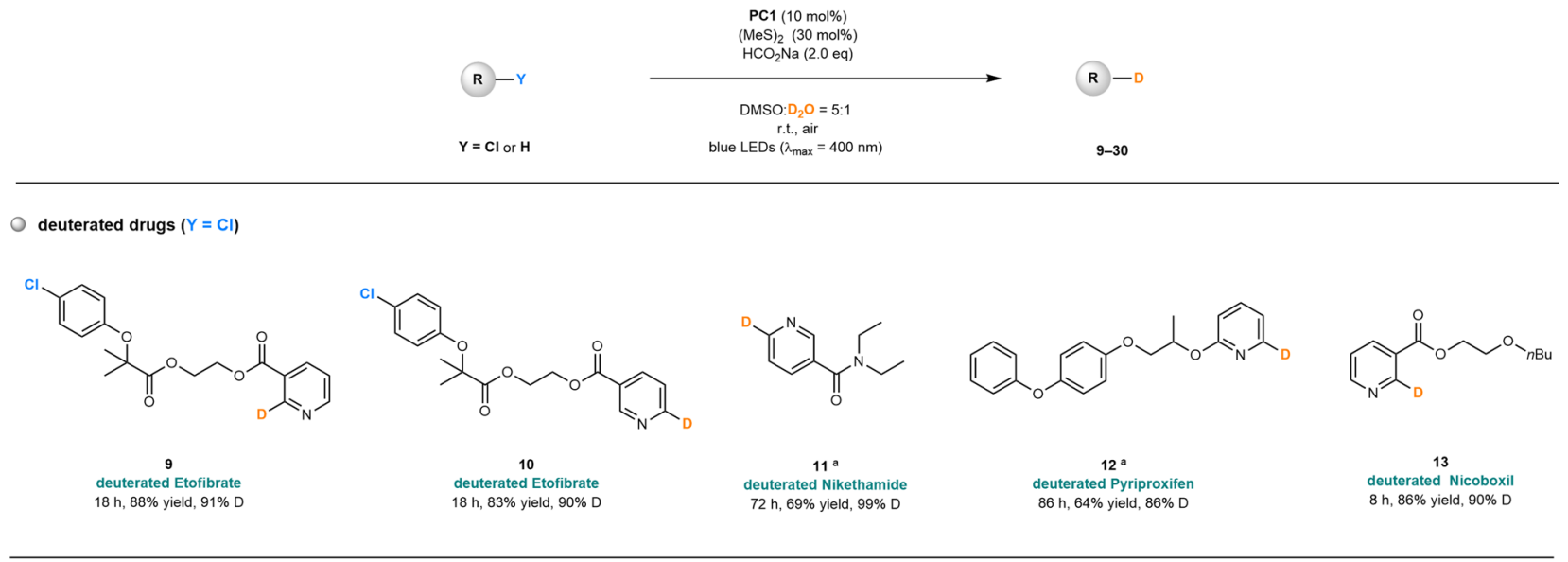

deuterated analogs of drug-like molecules $(Y=C l)$<smiles>O=C(Nc1ccccc1-c1cccc(Cl)c1)c1cccnc1</smiles>

14
from Boscalid $10 \mathrm{~h}, 89 \%$ yield, $88 \% \mathrm{D}$

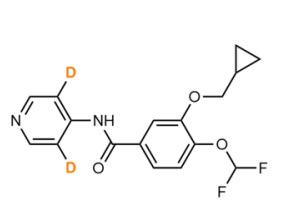

19
from Roflumilast $48 \mathrm{~h}, 61 \%$ yield, $72 \%$ D<smiles>CC(C)C1CCCCC1C(=O)c1ccc(O)cc1</smiles>

$$
\begin{gathered}
15 \\
\text { from L-Menthol derivative } \\
12 \mathrm{~h}, 85 \% \text { yield, } 86 \% \mathrm{D}
\end{gathered}
$$<smiles>[2H]c1ccc(C=O)cn1</smiles><smiles>Cc1c(C)c2c(c(C)c1OC(=O)C=O)CCC(C)(CCC[C@H](C)CCC[C@H](C)CCCC(C)C)O2</smiles><smiles>CC(=O)Oc1ccc(CCNC(=O)c2ccc(Br)cc2)cc1</smiles>

16
from Bezafibrate derivative
$12 \mathrm{~h}, 70 \%$ yield, $82 \% \mathrm{D}$<smiles>CCOCCCNC(=O)c1ccc(O)nc1</smiles>

$$
\begin{gathered}
17 \\
\text { deuterated Pikamilone ester } \\
48 \mathrm{~h}, 65 \% \text { yield, } 89 \% \text { D }
\end{gathered}
$$
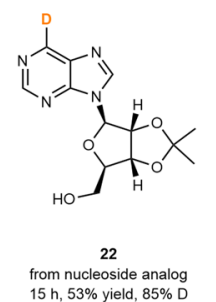

$15 \mathrm{~h}, 53 \%$ yield, $85 \% \mathrm{D}$

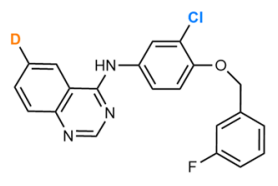

18 synthetic intermediate
of Lapatinib ditosylate

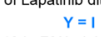
$12 \mathrm{~h}, 78 \%$ yield, $73 \% \mathrm{D}$
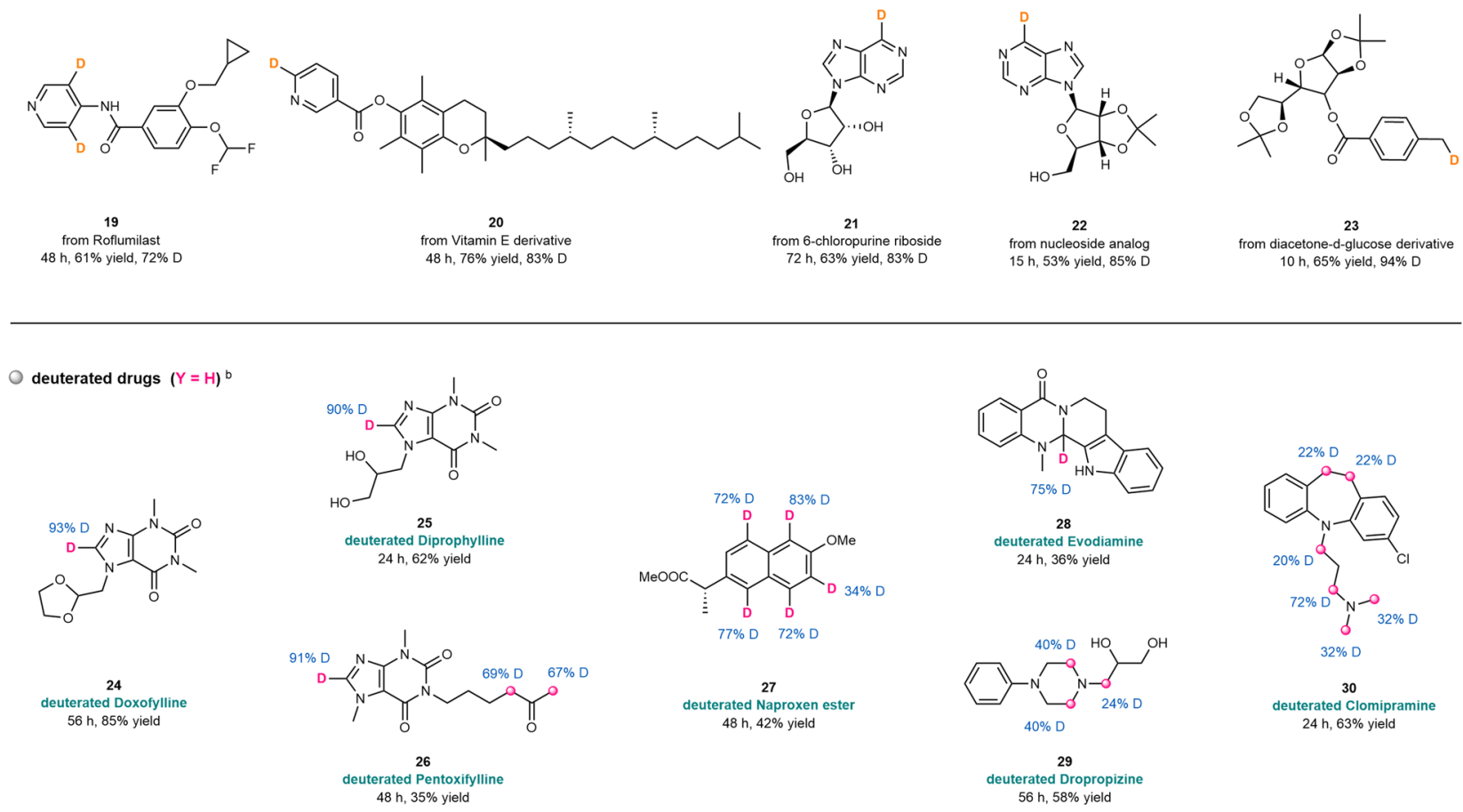

ig. 9 Synthetic application to D-labeled bioactive molecules and drugs. apC4 (20 mol\%), $(n P r S)_{2}(30 \mathrm{~mol} \%)$, in argon. ${ }^{b} \mathbf{P C 2}(10 \mathrm{~mol} \%),(n P r S)_{2}$ (60 mol\%), $\mathrm{HCO}_{2} \mathrm{Na}$ (4.0 eq). PC, photocatalyst; eq, equivalent; r.t., room temperature; DMSO, dimethyl sulfoxide.

of an L-menthol derivative (product 15), Bezafibrate derivative (product 16), Pikamilone ester (product 17), a synthetic intermediate of Lapatinib ditosylate ( $\mathrm{Y}=\mathrm{I}$, product 18), Roflumilast (product 19), Vitamin E derivative (product 20), 6-chloropurine riboside (product 21), and nucleoside analog (product 22) all proceeded smoothly, leading to the formation of deuterated products in $53-89 \%$ yield and with $72-88 \%$ D-inc. The diacetone-d-glucose derivative, an aliphatic chlorinated biomolecule, was also found to be well tolerated in the reaction and provided product $\mathbf{2 3}$ in $65 \%$ yield and $94 \% \mathrm{D}$-inc.

$\mathrm{H} / \mathrm{D}$ exchange of $\mathrm{C}\left(\mathrm{sp}^{3}\right)-\mathrm{H}$ or $\mathrm{C}\left(\mathrm{sp}^{2}\right)-\mathrm{H}$ bonds is a appealing access to deuterated molecules, but its application in D-labeling of pharmaceutical compounds remains a formidably difficult problem $^{25}$. Interestingly, this photocatalytic system could be used for direct H/D exchange of some drug and drug-like molecules. Under modified conditions in the presence of PC2 as 
the photocatalyst, the $\mathrm{C}\left(\mathrm{sp}^{2}\right)-\mathrm{H}$ bond located on the imidazole moiety of Doxofyline, an injectable drug for treatment of asthma, was selectively deuterated, delivering product $\mathbf{2 4}$ in $85 \%$ yield and 93\% D-inc. within $56 \mathrm{~h}$. The reactions of its derivatives, Diprophylline and Pentoxifylline, gave similar results and afforded product $\mathbf{2 5}$ and $\mathbf{2 6}$ with good deuterium incorporation, respectively. Such H/D exchange phenomena was observed in the photochemical reactions of Naproxen ester (product 27), Evodiamine (product 28), Dropropizine (product 29), and Chomipramine (product 30), in which one or more $\mathrm{C}\left(\mathrm{sp}^{2}\right)-\mathrm{H} / \mathrm{C}$ $\left(\mathrm{sp}^{3}\right)-\mathrm{H}$ bonds were deuterated. These outcomes further demonstrated synthetic utility of this method in D-labeling of structurally complex biomolecules.

\section{Discussion}

We have designed an organophotocatalytic system by merging arylamine-based photocatalysis and disulfide catalysis. The conjugate aryl amines, such as PC1 and PC2 which have not been used as photocatalysts in previous studies, are introduced as strongly reducing photoredox catalysts to initiate cleavage of $\mathrm{C}-\mathrm{Cl}$ bonds, at the same time as energy transfer catalysts to induce homolysis of the disulfide cocatalysts. Common alkyl disulfides are involved to enable a high level of deuterium incorporation. Sodium formate is employed as a mild electron and hydrogen sacrificial agent to promote the radical transformations and to close the catalytic cycles. This strategy allows us establish an efficient channel for deuterium transfer, and suppressing side reactions such as selfcoupling and elimination. Under very mild reaction conditions (visible light, $\mathrm{D}_{2} \mathrm{O} / \mathrm{DMSO}$, room temperature, in air, benign byproducts such as $\mathrm{CO}_{2}$ ), a wide range of aryl chlorides, alkyl chlorides, and other halides including many bioactive molecules ( $>90$ examples) can be converted to deuterated products in good yields and with up to $99 \% \mathrm{D}$-incorporation. Moreover, precise siteselectivity toward $\mathrm{C}-\mathrm{Cl}$ bonds of polychlorinated compounds that have little or no difference in polarity or other features has been observed. The successful production to deuterated drugs and other bioactive molecules as well as application to $\mathrm{H} / \mathrm{D}$ exchange of $\mathrm{C}$ $\left(\mathrm{sp}^{2}\right)-\mathrm{H}$ or $\mathrm{C}\left(\mathrm{sp}^{3}\right)-\mathrm{H}$ bonds with $\mathrm{D}_{2} \mathrm{O}$ demonstrate considerable potential of this method in pharmaceutical chemistry.

\section{Methods}

General procedure for deuterodehalogenation of aryl chlorides. A dried $5 \mathrm{~mL}$ glass vial was charged with aryl chlorides $(0.20 \mathrm{mmol})$, photocatalyst $\mathbf{P C 1}(8.7 \mathrm{mg}$, $0.020 \mathrm{mmol}),(\mathrm{MeS})_{2}(6 \mu \mathrm{L}, 0.060 \mathrm{mmol}), \mathrm{HCO}_{2} \mathrm{Na}(27.2 \mathrm{mg}, 0.40 \mathrm{mmol}), \mathrm{D}_{2} \mathrm{O}$ $(200 \mu \mathrm{L})$ and DMSO $(1.0 \mathrm{~mL})$ under air and then performed in a sealed vessel. The glass vial was positioned approximately $3 \mathrm{~cm}$ away from a $50 \mathrm{~W}$ blue LEDs lamp $\left(\lambda_{\max }=400 \mathrm{~nm}\right)$. After being stirred at room temperature $\left(\sim 30^{\circ} \mathrm{C}\right.$ under irradiation) for the indicated time, the reaction mixture was purified by flash chromatography on silica gel to afford product.

\section{General procedure for deuterodehalogenation of alkyl chlorides. A dried $5 \mathrm{~mL}$ glass vial was charged with alkyl chlorides $(0.20 \mathrm{mmol})$, photocatalyst PC4 $(11.3 \mathrm{mg}, 0.040 \mathrm{mmol}),(n \mathrm{PrS})_{2}(10 \mu \mathrm{L}, 0.060 \mathrm{mmol}), \mathrm{HCO}_{2} \mathrm{Na}(27.2 \mathrm{mg}, 0.40$ $\mathrm{mmol}), \mathrm{D}_{2} \mathrm{O}(200 \mu \mathrm{L})$ and DMSO $(1.0 \mathrm{~mL})$ under air and then performed in a sealed vessel. The glass vial was positioned $\sim 3 \mathrm{~cm}$ away from a $50 \mathrm{~W}$ blue LEDs lamp $\left(\lambda_{\max }=400 \mathrm{~nm}\right)$. After being stirred at room temperature $\left(\sim 30^{\circ} \mathrm{C}\right.$ under irradiation) for the indicated time, the reaction mixture was purified by flash chromatography on silica gel to afford product.}

\section{Data availability}

The authors declare that the data supporting the findings of this study are available within this article and its Supplementary Information file, or from the corresponding author upon reasonable request. The experimental procedures and characterization of all new compounds are provided in Supplementary Information.

Received: 2 February 2021; Accepted: 30 March 2021; Published online: 17 May 2021

\section{References}

1. Wiberg, K. B. The deuterium isotope effect. Chem. Rev. 55, 713-743 (1955)

2. Simmons, E. M. \& Hartwig, J. F. On the interpretation of deuterium kinetic isotope effects in $\mathrm{C}-\mathrm{H}$ bond functionalizations by transition-metal complexes. Angew. Chem. Int. Ed. 51, 3066-3072 (2012).

3. Lukin, S. et al. Isotope labeling reveals fast atomic and molecular exchange in mechanochemical milling reactions. J. Am. Chem. Soc. 141, 1212-1216 (2019).

4. McAtee, R. C., Noten, E. A. \& Stephenson, C. R. J. Arene dearomatization through a catalytic $N$-centered radical cascade reaction. Nat. Commun. 11, 2528 (2020).

5. Plesniak, M. P. et al. Samarium(II) folding cascades involving hydrogen atom transfer for the synthesis of complex polycycles. Nat. Commun. 9, 4802 (2018)

6. Watile, R. A. et al. Intramolecular substitutions of secondary and tertiary alcohols with chirality transfer by an iron(III) catalyst. Nat. Commun. 10, 3826 (2019).

7. Kim, J. H., Greßies, S. \& Glorius, F. Cooperative Lewis Acid/Cp*Co ${ }^{\text {III }}$ catalyzed $\mathrm{C}-\mathrm{H}$ bond activation for the synthesis of isoquinolin-3-ones. Angew. Chem. Int. Ed. 55, 5577-5581 (2016).

8. Miyashita, M., Sasaki, M., Hattori, I., Sakai, M. \& Tanino, K. Total synthesis of norzoanthamine. Science 305, 495-499 (2004).

9. Atzrodt, J., Derdau, V., Fey, T. \& Zimmermann, J. The renaissance of H/D exchange. Angew. Chem. Int. Ed. 46, 7744-7765 (2007).

10. Emmert, M. H., Gary, J., Villalobos, J. \& Sanford, M. Platinum and palladium complexes containing cationic ligands as catalysts for arene H/D exchange and oxidation. Angew. Chem. Int. Ed. 49, 5884-5886 (2010).

11. Pieters, G. et al. Regioselective and stereospecific deuteration of bioactive aza compounds by the use of ruthenium nanoparticles. Angew. Chem. Int. Ed. 53, 230-234 (2014).

12. Quasdorf, K. W., Huters, A. D., Lodewyk, M. W., Tantillo, D. J. \& Garg, N. K. Total synthesis of oxidized welwitindolinones and (-)- $N$ methylwelwitindolinone C isonitrile. J. Am. Chem. Soc. 134, 1396-1399 (2012).

13. Scheppele, S. E. Kinetic isotope effects as a valid measure of structurereactivity relations. Isotope effects and nonclassical theory. Chem. Rev. 72, 511-532 (1972).

14. Wacker, S. A., Kashyap, S., Li, X. \& Kapoor, T. M. Examining the mechanism of action of a kinesin inhibitor using stable isotope labeled inhibitors for crosslinking (SILIC). J. Am. Chem. Soc. 133, 12386-12389 (2011).

15. Ye, Q. et al. Large anisotropy and effect of deuteration on permittivity in an olefin copper(I) complex. Angew. Chem. Int. Ed. 46, 6852-6856 (2007).

16. Katsnelson, A. Heavy drugs draw heavy interest from pharma backers. Nat. Med. 19, 656 (2013).

17. Cress, B. F. et al. Heavy heparin: a stable isotope enriched, chemoenzymatically-synthesized, poly-component drug. Angew. Chem. Int. Ed. 58, 5962-5966 (2019).

18. Palazzolo, A. et al. Efficient access to deuterated and tritiated nucleobase pharmaceuticals and oligonucleotides using hydrogen-isotope exchange. Angew. Chem. Int. Ed. 58, 4891-4895 (2019).

19. Elmore, C. S. \& Bragg, R. A. Isotope chemistry; a useful tool in the drug discovery arsenal. Bioorg. Med. Chem. Lett. 25, 167-171 (2015).

20. Isin, E. M., Elmore, C. S., Nilsson, G. N., Thompson, R. A. \& Weidolf, L. Use of radiolabeled compounds in drug metabolism and pharmacokinetic studies. Chem. Res. Toxicol. 25, 532-542 (2012).

21. Mullard, A. Deuterated drugs draw heavier backing. Nat. Rev. Drug Discov. 15, 219-221 (2016).

22. Schmidt, C. First deuterated drug approved. Nat. Biotechnol. 35, 493-494 (2017).

23. Gant, T. G. Using deuterium in drug discovery: leaving the label in the drug. J. Med. Chem. 57, 3595-3611 (2014).

24. Meanwell, N. A. Synopsis of some recent tactical application of bioisosteres in drug design. J. Med. Chem. 54, 2529-2591 (2011).

25. Loh, Y. Y. et al. Photoredox catalyzed deuteration and tritiation of pharmaceutical compounds. Science 358, 1182-1187 (2017).

26. Pony, Yu,R., Hesk, D., Rivera, N., Pelczer, I. \& Chirik, P. J. Iron catalysed tritiation of pharmaceuticals. Nature 529, 195-199 (2016).

27. Liu, W. et al. Mesoionic carbene (MIC)-catalyzed H/D exchange at formyl groups. Chem. 5, 2484-2494 (2019)

28. Geng, H. et al. Practical synthesis of $\mathrm{C} 1$ deuterated aldehydes enabled by NHC catalysis. Nat. Catal. 2, 1071-1077 (2019).

29. Zhang, M., Yuan, X.-A., Zhu, C. \& Xie, J. Deoxygenative deuteration of carboxylic acids with $\mathrm{D}_{2} \mathrm{O}$. Angew. Chem. Int. Ed. 58, 312-316 (2019).

30. Chang, Y. et al. Catalytic deuterium incorporation within metabolically stable $\beta$-Amino C-H bonds of drug molecules. J. Am. Chem. Soc. 141, 14570-14575 (2019).

31. Zhou, R. et al. Visible-light-mediated deuteration of silanes with deuterium oxide. Chem. Sci. 10, 7340-7344 (2019).

32. Espinal-Viguri, M., Neale, S. E., Coles, N. T., Macgregor, S. A. \& Webster, R. L. Room temperature iron-catalyzed transfer hydrogenation and regioselective deuteration of carbon-carbon double bonds. J. Am. Chem. Soc. 141, 572-582 (2019). 
33. Codolà, Z. et al. Design of iron coordination complexes as highly active homogenous water oxidation catalysts by deuteration of oxidation-sensitive sites. J. Am. Chem. Soc. 141, 323-333 (2019).

34. Kurimoto, A., Sherbo, R. S., Cao, Y., Loo, N. W. X. \& Berlinguette, C. P. Electrolytic deuteration of unsaturated bonds without using $\mathrm{D}_{2}$. Nat. Catal. 3, 719-726 (2020).

35. Koniarczyk, J. L., Hesk, D., Overgard, A., Davies, I. W. \& McNally, A. A general strategy for site-selective incorporation of deuterium and tritium into pyridines, diazines, and pharmaceuticals. J. Am. Chem. Soc. 140, 1990-1993 (2018).

36. Puleo, T. R., Strong, A. J. \& Bandar, J. S. Catalytic a-selective deuteration of styrene derivatives. J. Am. Chem. Soc. 141, 1467-1472 (2019)

37. Liu, C., Han, S., Li, M., Chong, X. \& Zhang, B. Electrocatalytic deuteration of halides with $\mathrm{D}_{2} \mathrm{O}$ as the deuterium source over a copper nanowire arrays cathode. Angew. Chem. Int. Ed. 59, 18527-18531 (2020).

38. Wang, X., Zhu, M.-H. \& Liu, W.-B. Potassium alkoxide/disilane-mediated dehalogenative deuteration. Synlett 30, 1003-1007 (2019).

39. Yu, Y. \& Zhang, B. Photocatalytic deuteration of halides using $\mathrm{D}_{2} \mathrm{O}$ over CdSe porous nanosheets: a mild and controllable route to deuterated molecules. Angew. Chem. Int. Ed. 57, 5590-5592 (2018).

40. Soulard, V., Villa, G., Vollmar, D. P. \& Renaud, P. Radical deuteration with $\mathrm{D}_{2} \mathrm{O}$ : catalysis and mechanistic insights. J. Am. Chem. Soc. 140, 155-158 (2018).

41. Wang, X. et al. General and practical potassium methoxide/disilane-mediated dehalogenative deuteration of (hetero) arylhalides. J. Am. Chem. Soc. 140, 10970-10974 (2018)

42. Liu, C. et al. Controllable deuteration of halogenated compounds by photocatalytic $\mathrm{D}_{2} \mathrm{O}$ splitting. Nat. Commun. 9, 80 (2018).

43. Xia, A., Xie, X., Hu, X., Xu, W. \& Liu, Y. Dehalogenative deuteration of unactivated alkyl halides using $\mathrm{D}_{2} \mathrm{O}$ as the deuterium source. J. Org. Chem. 84, 13841-13857 (2019).

44. Shao, T. et al. Photoredox-catalyzed enantioselective a-deuteration of azaarenes with D2O. iScience 16, 410-419 (2019).

45. Dong, Y. et al. Plasmon-enhanced deuteration under visible-light irradiation. ACS Nano 13, 10754-10760 (2019).

46. Kuriyama, M. et al. Deuterodechlorination of aryl/heteroaryl chlorides catalyzed by a Palladium/unsymmetrical NHC system. J. Org. Chem. 81, 8934-8946 (2016).

47. Lambert, F. L. \& Ingall, G. B. Voltammetry of organic halogen compounds. IV. The reduction of organic chlorides at the vitreous (glassy) carbon electrode. Tetrahedron Lett. 3231-3234 (1974).

48. Yin, H. et al. The hexachlorocerate(III) anion: a potent, benchtop stable, and readily available ultraviolet a photosensitizer for aryl chlorides. J. Am. Chem. Soc. 138, 16266-16273 (2016).

49. Yin, H., Carroll, P. J., Anna, J. M. \& Schelter, E. J. Luminescent Ce(III) complexes as stoichiometric and catalytic photoreductants for halogen atom abstraction reactions. J. Am. Chem. Soc. 137, 9234-9237 (2015).

50. Cybularczyk-Cecotka, M., Szczepanik, J. \& Giedyk, M. Photocatalytic strategies for the activation of organic chlorides. Nat. Catal. 3, 872-886 (2020).

51. Pagire, S. K., Föll, T. \& Reiser, O. Shining visible light on vinyl halides: expanding the horizons of photocatalysis. Acc. Chem. Res. 53, 782-791 (2020).

52. Kim, H., Kim, H., Lambert, T. \& Lin, S. Reductive electrophotocatalysis: merging electricity and light to achieve extreme reduction potentials. J. Am. Chem. Soc. 142, 2087-2092 (2020).

53. Ghosh, I., Ghosh, T., Bardagi, J. I. \& König, B. Reduction of aryl halides by consecutive visible light-induced electron transfer processes. Science 346, 725-728 (2014).

54. Li, Y., Lei, M. \& Gong, L. Photocatalytic regio- and stereoselective C( $\left.\mathrm{sp}^{3}\right)-\mathrm{H}$ functionalization of benzylic and allylic hydrocarbons as well as unactivated alkanes. Nat. Catal. 2, 1016-1026 (2019).

55. Han, B., Li, Y., Yu, Y. \& Gong, L. Photocatalytic enantioselective $\alpha$ aminoalkylation of acyclic imine derivatives by a chiral copper catalyst. Nat. Commun. 10, 3804 (2019).

56. Li, Y. et al. Copper(II)-catalyzed asymmetric photoredox reactions: enantioselective alkylation of imines driven by visible light. J. Am. Chem. Soc. 140, 15850-15858 (2018).

57. Shen, X. et al. A chiral nickel DBFOX complex as a bifunctional catalyst for visible-light-promoted asymmetric photoredox reactions. Chem. Sci. 9, 4562-4568 (2018).

58. Zhou, K., Yu, Y., Lin, Y.-M., Li, Y. \& Gong, L. Copper-catalyzed aerobic asymmetric cross-dehydrogenative coupling of $\mathrm{C}\left(\mathrm{sp}^{3}\right)-\mathrm{H}$ bonds driven by visible light. Green. Chem. 22, 4597-4603 (2020).

59. McCarthy, B. G. et al. Structure-property relationships for tailoring phenoxazines as reducing photoredox catalysts. J. Am. Chem. Soc. 140 5088-5101 (2018).

60. Noto, N., Koike, T. \& Akita, M. Visible light-triggered monofluoromethylation of alkenes by strongly reducing 1,4-bis(diphenylamino)naphthalene photoredox catalysis. ACS Catal. 9, 4382-4387 (2019).
61. Vishnoi, P., Sen, S., Patwari, G. N. \& Murugavel, R. Charge transfer aided selective sensing and capture of picric acid by triphenylbenzenes. N. J. Chem. 39, 886-892 (2015).

62. Constantin, T. et al. Aminoalkyl radicals as halogen-atom transfer agents for activation of alkyl and aryl halides. Science 367, 1021-1026 (2020).

63. Boyington, A. J., Seath, C. P., Zearfoss, A. M., Xu, Z. \& Jui, N. T. Catalytic strategy for regioselective arylethylamine synthesis. J. Am. Chem. Soc. 141 4147-4153 (2019).

64. Patehebieke, Y. An overview on disulfide-catalyzed and -cocatalyzed photoreactions. Beilstein J. Org. Chem. 16, 1418-1435 (2020).

65. Giedyk, M. et al. Photocatalytic activation of alkyl chlorides by assemblypromoted single electron transfer in microheterogeneous solutions. Nat. Catal. 3, 40-47 (2020).

66. Golding, W. A., Pearce-Higgins, R. \& Phipps, R. J. Site-selective crosscoupling of remote chlorides enabled by electrostatically directed palladium catalysis. J. Am. Chem. Soc. 140, 13570-13574 (2018)

67. Golding, W. A., Schmitt, H. L. \& Phipps, R. J. Systematic variation of ligand and cation parameters enables site-selective C-C and C-N cross-coupling of multiply chlorinated arenes through substrate-ligand electrostatic interactions. J. Am. Chem. Soc. 142, 21891-21898 (2020).

68. Desaintjean, A. et al. Regioselective bromine/magnesium-exchange for selective functionalization of polyhalogenated aromatics and heterocycles. Angew. Chem. Int. Ed. 60, 1513-1518 (2021).

69. Sandfort, F., Knecht, T., Pinkert, T., Daniliuc, C. G. \& Glorius, F. Site-selective thiolation of (multi)halogenated heteroarenes. J. Am. Chem. Soc. 142, 6913-6919 (2020).

70. $\mathrm{Xu}, \mathrm{Y}$. et al. Aldehyde oxidase mediated metabolism in drug-like molecules: a combined computational and experimental study. J. Med. Chem. 60, 2973-2982 (2017).

71. Li, Z. et al. Redirecting abiraterone metabolism to fine-tune prostate cancer anti-androgen therapy. Nature 533, 547-551 (2016).

72. McGrath, N. A., Brichacek, M. \& Njardarson, J. T. A graphical journey of innovative organic architectures that have improved our lives. J. Chem. Educ. 87, 1348-1349 (2010).

73. Teders, M. et al. The energy-transfer-enabled biocompatible disulfide-ene reaction. Nat. Chem. 10, 981-988 (2018).

74. Proctor, R. S. J., Davis, H. J. \& Phipps, R. J. Catalytic enantioselective miniscitype addition to heteroarenes. Science 360, 419-422 (2018).

75. Nagaki, A., Ichinari, D. \& Yoshida, J. Three-component coupling based on flash chemistry. Carbolithiation of benzyne with functionalized aryllithiums followed by reactions with electrophiles. J. Am. Chem. Soc. 136, 12245-12248 (2014).

\section{Acknowledgements}

We gratefully acknowledge funding from the National Natural Science Foundation of China (grant no. 22071209, 22071206), the Natural Science Foundation of Fujian Province of China (grant no. 2017J06006), and the Fundamental Research Funds for the Central Universities (grant no. 20720190048).

\section{Author contributions}

Y.L. and L.G. designed and conceived the project. Y.L. and Z.Y. conducted all the synthetic and catalytic reactions. Y.L., Z.Y., Y.-M.L., and L.G. analyzed and interpreted the experimental data. Z.Y. designed and performed the theoretical calculations. Y.L. and Y.Z. performed the HRMS experiments and analyzed the data. L.G. prepared the manuscript. Y.L. and Z.Y. prepared the Supplementary Information.

\section{Competing interests}

The authors declare no competing interests.

\section{Additional information}

Supplementary information The online version contains supplementary material available at https://doi.org/10.1038/s41467-021-23255-0.

Correspondence and requests for materials should be addressed to L.G.

Peer review information Nature Communications thanks Huiying Zeng and the other anonymous reviewers for their contribution to the peer review of this work. Peer reviewer reports are available.

Reprints and permission information is available at http://www.nature.com/reprints

Publisher's note Springer Nature remains neutral with regard to jurisdictional claims in published maps and institutional affiliations. 
(c) (i) Open Access This article is licensed under a Creative Commons Attribution 4.0 International License, which permits use, sharing, adaptation, distribution and reproduction in any medium or format, as long as you give appropriate credit to the original author(s) and the source, provide a link to the Creative Commons license, and indicate if changes were made. The images or other third party material in this article are included in the article's Creative Commons license, unless indicated otherwise in a credit line to the material. If material is not included in the article's Creative Commons license and your intended use is not permitted by statutory regulation or exceeds the permitted use, you will need to obtain permission directly from the copyright holder. To view a copy of this license, visit http://creativecommons.org/ licenses/by/4.0/.

(C) The Author(s) 2021 